\title{
Unconventional Methods of Thermomechanical Treatment of Tool Steel
}

David Aisman, Katerina Opatova, Katerina Rubesova, Stepan Jenicek

Regional Technological Institut, University of West Bohemia 8, 30614 Plzen, Czech Republic, E-mail: daisman@vctt.zcu.cz, hstankov@vctt.zcu.cz, krubesov@vctt.zcu.cz, jeniceks@vctt.zcu.cz

Tool steels are traditional materials whose heat treatment routes are well-established. Despite that fact, unconventional treatment methods can be used, for instance for refining chromium carbides and general strengthening of the structure. One of the methods that considerably alter microstructure is semi-solid processing. By means of passing through the semi-solid state, the X210Cr12 steel (ČSN 19436) developed a microstructure of polyhedral austenite grains embedded in a carbide network. Forming of this material at an appropriate temperature led to recrystallization of the austenitic microstructure and to uniform distribution of carbides with a size of approximately $2 \mu \mathrm{m}$. By varying the rate of subsequent cooling, microstructures ranging from austenite to martensite could be obtained.

Keywords: semi-solid state, tool steel, dynamic recrystallization, metastable austenite

\section{Acknowledgement}

This paper includes results created within the projects SGS-2015-028 Semi-solid Processing and New Structures without Carbide Net and TG02010011 Promoting Commercial Opportunities of UWB, sub-project Unconventional Production of Tool Steels Reinforced by Submicron-carbides. Both are subsidised from specific resources of the state budget for research and development, the project SGS-2015-028 through the Ministry of Education, Youth and Sports and the project TG02010011 through the Technology Agency of the Czech Republic and belongs to the GAMA programme.

\section{References}

[1] AIŠMAN, D., MAŠEK, B., JENÍČEK, Š., (2015). Unvoncentional Microstructures Tool Steel Obtained by SemiSolid Processing and Subsequement Heat Treatment, S2P 2014, pp. 235-240, Pfaffikon, Schwitzerland: Trans Tech Publications Ltd., 2015.

[2] HIRT, G., BLECK, W., BÜHRIG-POLACZEK, A., SHIMAHARA, H., PÜTTGEN, W., AFRATH. C. (2006). Semi Solid Casting and Forging of Steel. Solid State Phenomena Vols. 116-117, pp. 34-43.

[3] Semi-Solid Processing (SSP) of Alloys: Part Two, (2013) Total material database, http://www.totalmateria.com/page.aspx?ID=CheckArticle\&site $=\mathrm{ktn} \& \mathrm{LN}=\mathrm{EN} \& N M=317$, (acces 09.11.2016)

[4] MAŠEK, B.; AIŠMAN, D.; JIRKOVÁ, H. (2014). Microstructure of tool upon combined semi-solid processing and thermomechanical treatment, in: Journal of Alloys and Compounds, Vol. 586, pp. 265-167

[5] JMatPro, Release 9.0, Sente Software Ltd., 2016

[6] BRYKSÍ STUNOVÁ, B., BRYKSÍ, V. (2015). Phase Segregation during Processing of Semi-Solid Slurry by Rheocasting Method SEED, Manufacturing Technology, Volume 15, No. 4, pp 515-520, ISSN 1213-2489

[7] AISMAN D., JIRKOVÁ H., RUBESOVA K., JENICEK S. (2016). Mini-Thixoforming of Low-Carbon HighAlloy Steel. Manufacturing Technology, Volume 16, No. 5, pp 140-144, ISSN 1213-2489 